\title{
APLICAÇĀO DA ENGENHARIA DIAGNÓSTICA NO ESTUDO DE CASO DA INSPEÇĀO PREDIAL EM RESIDÊNCIAS MULTIFAMILIARES DO MUNICÍPIO DE GARANHUNS-PE
}

\author{
PINHEIRO, DAYANNE MICHELLE DA SILVA \\ Estudante, Graduação \\ Faculdades Integradas de Garanhuns (AESGA) \\ Garanhuns-PE; Brasil \\ day2014michelle@hotmail.com
}

\author{
NASCIMENTO, KAIKE MANOEL BARROS DO \\ Professor, Mestre \\ Faculdades Integradas de Garanhuns (AESGA) \\ Garanhuns-PE; Brasil \\ kaike41@hotmail.com \\ NÓBREGA, ANA CECÍLIA VIEIRA DA \\ Professora, Doutora \\ Faculdade Federal de Pernambuco (UFPE/CAA) \\ Caruaru-PE; Brasil \\ anacecilia.nobrega@gmail.com
}

\author{
APOLONIO, PRISCILA HONORIO \\ Professora, Mestra \\ Faculdades Integradas de Garanhuns (AESGA) \\ Garanhuns-PE; Brasil \\ apolonio.priscila@gmail.com
}

\author{
CARNEIRO, ARNALDO MANOEL PEREIRA \\ Professor, Doutor \\ Faculdade Federal de Pernambuco (UFPE) \\ Recife-PE; Brasil \\ arnaldo2164@hotmail.com
}

\section{RESUMO}

A Engenharia Diagnóstica faz aplicação de ferramentas que facilita a inspeção predial, constatando anomalias e falhas no local de estudo. O presente trabalho consiste na vistoria de residências multifamiliares, situadas no município de Garanhuns-PE, cujo objetivo é reconhecer as manifestações patológicas, adotando como metodologia no processo de inspeção a classificação do grau de risco, anomalias, falhas e a elaboração da matriz GUT (Gravidade, Urgência e Tendência). O local de estudo é um condomínio residencial, constituído por 4 blocos, denominados blocos A, B, C e D, todos de alvenaria estrutural, padronizados em térreo e mais 3 pavimentos tipo. Detectou-se durante a inspeção, manifestações patológicas, denominadas: desplacamento de revestimento cimentício, deterioração das juntas de assentamento, apresentados somente nos blocos A e B, manchas, fissuras e infiltração encontrados em todos os blocos. As anomalias constatadas nos blocos foram de $87 \%$ endógenas provenientes de vícios de projeto, material e execução, e 13\% exógenas, provocados por danos de terceiros, onde a classificação do grau de risco teve sua predominância regular com $61 \%$ causando uma deterioração precoce no local, a mínimo teve $33 \%$ ocasionando riscos de causas pequenas e crítico com $6 \%$ acarretando consequentemente uma preocupação pelo risco a segurança e saúde dos moradores. Diante dos vícios construtivos citados, a ordem do GUT priorizou o bloco B para reparos imediatos de acordo com o que foi apresentado. Em virtude dos fatos mencionados constatou-se a necessidade de efetuar medidas para o combate dessas anomalias e procedimentos que efetuassem o prolongamento da durabilidade, desempenho e vida útil dos blocos.

Palavras-chave: Engenharia Diagnóstica, Inspeção, Manifestações Patológicas.

\section{RESUME}

Diagnostic Engineering uses tools that facilitate building inspection, finding anomalies and failures in the study site. The present work consists in the inspection of multifamily residences, located in the municipality of Garanhuns-PE, whose objective is to recognize the pathological manifestations, adopting as methodology in the inspection process the classification of the degree of risk, anomalies, failures and the elaboration of the GUT matrix ( Gravity, Urgency and Tendency). The study site is a residential condominium, consisting of 4 blocks, called blocks A, B, C and D, all of structural masonry, standardized on the ground floor and 3 more floors. During the inspection, pathological manifestations were detected, namely: debarking of cementitious lining, deterioration of the laying joints, presented only in blocks A and B, stains, cracks and infiltration found in all blocks. The anomalies found in the blocks were $87 \%$ endogenous due to flaws in design, material and execution, and $13 \%$ exogenous, caused by damage from third parties, where the classification of the degree of risk had its regular predominance with $61 \%$ causing an early deterioration in the At the local level, the minimum was $33 \%$ causing risks of small causes and critical with $6 \%$ consequently causing a concern for the safety and health of residents. In view of the aforementioned construction defects, the GUT order prioritized block B for immediate repairs according to what was presented. In view of the aforementioned facts, it was noted the need to take measures to combat these anomalies and procedures that would prolong the durability, performance and useful life of the blocks. Keywords: Diagnostic Engineering, Inspection, Pathological Manifestations. 


\section{INTRODUÇÃO}

No estudo do combate contra manifestações patológicas em edificações, a engenharia diagnóstica foi se constituindo com o intuito de revelar a verdade por trás de problemas que comprometem aspectos de segurança, habitabilidade e vida útil dos imóveis, a partir da utilização de ferramentas. Podendo obter um diagnóstico preciso das manifestações patológicas, além de classificar como vícios construtivos e manutenção, respectivamente, anomalia e falha, contribuindo para descobrir origem, causas e efeitos. Como informação complementar, a Engenharia Diagnóstica é comparada com a Medicina, de maneiras similares a respeito dos estudos para atestarem os seus diagnósticos e prescrições.

Segundo Vieira (2016), as edificações têm dado um verdadeiro exemplo de grande durabilidade, sob condições totalmente adversas, as estruturas de concreto não são eternas, pois se deterioram com o passar do tempo e não alcançam sua vida útil, comprovando, que tudo isso trata-se de uma crença. As manifestações patológicas são e serão o grande vilão das edificações, começando pela fase da degradação a sua estrutura por agentes químicos, físicos e biológicos, fazendo com que tenha um desempenho insatisfatório da vida útil. Desta maneira, a manifestação patológica se trata de uma expressão decorrente de um meio de degradação que são danos ocorridos nas edificações por diversas razões, a qual se manifesta em infiltrações, fissuras, umidade excessiva, entre outros.

Nos últimos anos, o desenvolvimento tecnológico e normativo do setor da construção civil segundo Ramalho et al. (2014) cresceu de forma acelerada, aumentando o número de edificações residenciais. O crescimento acelerado desse setor contribuiu para os intensos investimentos na construção civil e também aumentou a exigência na qualidade do desempenho das edificações. Desta forma, os profissionais da área de engenharia vem ganhando mais ênfase no mercado, contudo, como é um mercado que está em expansão, utiliza-se de uma demanda maior de mão de obra, muitas vezes não qualificada, fazendo com que a execução tenha uma queda na qualidade, por optar por mão de obra mais barata. Por consequência, há surgimento de várias manifestações patológicas, baixa qualidade, manutenções constantes, vida útil reduzida e até prováveis riscos para a sociedade. Diante disto, esta pesquisa teve como objetivo geral realizar inspeção predial de residências multifamiliares, descrevendo tudo o que foi visto.

\section{METODOLOGIA}

A metodologia aplicada ao estudo constitui-se exploratória, onde se seguiu com uma revisão bibliográfica e estudo de caso, aplicando uma das ferramentas da Engenharia Diagnóstica através da visita realizada ao condomínio residencial, salientando algumas manifestações patológicas, localizado no município de Garanhuns.

No artigo, primeiramente, trabalhou-se com o conhecimento da Engenharia Diagnóstica e suas exigências com relação à lei 13.032 que trata sobre a obrigatoriedade de vistorias periciais e manutenções periódicas, em edifícios de apartamentos e salas comerciais, no âmbito do Estado de Pernambuco, e dá outras providências, as normas da ABNT e IBAPE, as quais demostram particularidades sobre inspeção predial, durabilidade, vida útil, desempenho, manutenção e, por fim, a Engenharia Diagnóstica, que traz segurança aos usuários no que diz respeito as edificações, com relação à maneira como são inspecionadas após a sua execução. Logo em seguida, serão definidas as classificações das anomalias e falhas, grau de risco e a ordem de prioridade através da matriz GUT (Gravidade, Urgência e Tendência) e por fim, resultados recolhidos no local de estudo que se caracterizam com as manifestações encontradas, classificando-as de acordo com os itens acima.

Foi executado uma inspeção predial sobre as manifestações patológicas evidenciadas em todas as dependências comuns do local, seguido de registro fotográfico, para mostrar as implicações oriundas do projeto, execução e danos por terceiros. As anomalias foram classificadas quanto à origem das manifestações patológicas, ilustrado no quadro 1 .

Quadro 1 - Classificação das anomalias

\begin{tabular}{|c|c|}
\hline ASPECTO & CONCEITO \\
\hline ENDÓGENAS & Proveniente da própria edificação provenientes de vícios de (projeto, materiais e execução); \\
\hline EXÓGENAS & Seguidas de situações externas a edificação provocados por danos de terceiros; \\
\hline NATURAIS & Oriunda de estragos provocados pela natureza; \\
\hline FUNCIONAIS & $\begin{array}{c}\text { Consequência da deterioração de sistemas construtivos pelo enfraquecimento natural e, decorrente } \\
\text { a perda do desempenho da vida útil, oriundos do uso impróprio. }\end{array}$ \\
\hline
\end{tabular}

Fonte: Adaptado de Gomide, Pujadas e Fagunde Neto (2006). 
Através do reconhecimento e da classificação das anomalias e falhas no local se aplica o critério da Análise de Risco, que tem por objetivo identificar as detecções, vulnerabilidades, impactos, ameaças, contingências e ações essenciais para garantia da condições fundamentais de habitação. Com essa análise, o reconhecimento dos riscos é realizada com a constatação dos pontos que possibilitam a diminuição, transferência ou eliminação dos riscos, por meio de intervenções e estratégicas econômicas e viáveis, quadro 2.

Quadro 2 - Classificação do Grau de risco

\begin{tabular}{|c|c|}
\hline ASPECTO & CONCEITO \\
\hline CRÍTICO & $\begin{array}{c}\text { Provoca danos à segurança e saúde dos moradores e meio ambiente, ausência excessiva do } \\
\text { desempenho e funcionalidade da estrutura, aumentando o custo de manutenção e recuperação, } \\
\text { comprometendo a vida útil do local. }\end{array}$ \\
\hline $\begin{array}{c}\text { REGULA } \\
\text { R }\end{array}$ & $\begin{array}{c}\text { A uma deterioração precoce no local, provocando riscos de perda parcial de comportamento e utilidade } \\
\text { do edifício, sem prejudicar a operação direta. }\end{array}$ \\
\hline MÍNIMO & $\begin{array}{c}\text { Provoca riscos de causas pequenas, prejuízo a estética ou á atividades programada e planejadas, sem } \\
\text { incidência ou viabilidade de acontecimentos de riscos críticos e regulares. }\end{array}$ \\
\hline
\end{tabular}

Fonte: Adaptado de IBAPE/SP (2012)

Foi aplicado o modelo metodológico do quadro GUT, cuja classificação determina a ordem de prioridade das medidas corretivas necessárias para efetuar a reparação dos sistemas construtivos, dando um norte na investigação, priorizando o local mais afetado. No quadro 3, mostra todos os critérios que precisam ser seguidos para atribuir notas de acordo com as manifestações patológicas encontradas, considerando a vida útil (VU), a segurança estrutural e do usuário, juntamente com a funcionalidade. $\mathrm{O}$ grau de risco por Gravidade (G) está relacionado ao impacto que as anomalias e falhas oferecem à estrutura sob o ponto de vista da estabilidade estrutural e do usuário, desempenho e vida útil. A Urgência (U) determina a necessidade da adoção de medidas corretivas para não comprometer a estrutura, durabilidade e estabilidade. A Tendência (T) conjectura a evolução da anomalia ou falha caso não se adote nenhuma medida corretiva, ou preventiva. A ordem de prioridade é obtida através do somatório das notas dos critérios de Gravidade, Urgência e Tendência.

Quadro 3 - Método de Classificação de Prioridade
\begin{tabular}{|c|c|c|c|c|}
\hline GRAU & NOTA & GRAVIDADE & URGÊNCIA & TENDÊNCIA \\
\hline MÁXIMA & 10 & Risco à vida dos usuários, colapso da edificação, dano \\
ambiental grave. & $\begin{array}{c}\text { Evolução } \\
\text { imediata }\end{array}$ & $\begin{array}{c}\text { Em } \\
\text { ocorrência }\end{array}$ \\
\hline ALTA & 8 & $\begin{array}{c}\text { Risco de ferimentos aos usuários, avaria não recuperável na } \\
\text { edificação, contaminação localizada. }\end{array}$ & $\begin{array}{c}\text { Evolução em } \\
\text { curto prazo }\end{array}$ & A ocorrer \\
\hline MÉDIA & 6 & $\begin{array}{c}\text { Insalubridade aos usuários, deterioração elevada da } \\
\text { edificação, desperdício dos recursos naturais. }\end{array}$ & $\begin{array}{c}\text { Evolução em } \\
\text { médio prazo }\end{array}$ & $\begin{array}{c}\text { Prognóstico } \\
\text { para breve }\end{array}$ \\
\hline BAIXA & 3 & $\begin{array}{c}\text { Incomodo aos usuários, degradação da edificação, uso não } \\
\text { racional dos recursos naturais. }\end{array}$ & $\begin{array}{c}\text { Evolução em } \\
\text { longo prazo }\end{array}$ & $\begin{array}{c}\text { Prognóstico } \\
\text { para adiante }\end{array}$ \\
\hline MÍNIMA & 1 & Depreciação imobiliária. & Não evoluirá & Imprevisto \\
\hline
\end{tabular}

Fonte: Adaptada de Periard, (2011, apud APOLÔNIO, 2019)

Portanto, são estabelecidos níveis para classificar a inspeção predial, assim como, sua complexidade de acordo com IBAPE/SP (2012, p. 6) onde se comenta que a construção do laudo e tudo que acompanha a elaboração consistem em níveis de inspeção predial, que ajudam a acompanhar o andamento do seu trabalho, podem ser classificados como nível 1, nível 2, e nível 3.

O nível de inspeção predial realizado no local de estudo foi preconizado pela norma técnica do IBAPE/SP onde se enquadra como Nível 1, representada por análise simplificada dos fatos e sistemas construtivos vistoriados, com a identificação de suas anomalias e falhas aparentes, uma vez que não foram realizados testes, medições ou ensaios.

\subsection{Característica da área estudada}

A inspeção predial se refere a um condomínio residencial, localizado no município de Garanhuns-PE, sendo constituído por 04 blocos que são classificados por bloco A, bloco B, bloco C e bloco D, cada um é composto pela mesma padronização, 1 pavimento térreo, 03 pavimentos tipos, se diferenciando na quantidade de apartamentos por bloco, conforme é ilustrado na tabela 1. 
Tabela 1 - Número de apartamentos em cada bloco

\begin{tabular}{c|c|c|c|c|c}
\hline BLOCOS & TERREO & 1 ANDAR & 2 ANDAR & 3 ANDAR & TOTAL \\
\hline BLOCO A & 8 apartamentos & 8 apartamentos & 8 apartamentos & 8 apartamentos & 32 apartamentos \\
\hline BLOCO B & 8 apartamentos & 8 apartamentos & 8 apartamentos & 8 apartamentos & 32 apartamentos \\
\hline BLOCO C & 4 apartamentos & 4 apartamentos & 4 apartamentos & 4 apartamentos & 16 apartamentos \\
\hline BLOCO D & 4 apartamentos & 4 apartamentos & 4 apartamentos & 4 apartamentos & 16 apartamentos \\
\hline
\end{tabular}

Fonte: Dos autores (2020)

Os estacionamentos têm suporte para o número total de apartamento em cada bloco. A área comum é toda murada, constituída por uma guarita e três portões, tendo apenas uma entrada e saída.

Quadro 4 - Informações complementares do Condomínio

\begin{tabular}{|c|c|}
\hline \multicolumn{2}{|c|}{ DADOS DO CONDOMÍNIO RESIDENCIAL } \\
\hline TIPO DO IMOVEL & Residencial \\
\hline TIPO DA EDIFICAÇÃO & Multifamiliar \\
\hline ALVENARIA ESTRUTURAL de concreto \\
\hline REVESTIMENTO DAS FACHADAS & $\begin{array}{c}\text { Reboco em argamassa mista, produzida na obra, com } \\
\text { acabamento em textura tipo grafiato e detalhes em } \\
\text { revestimento cerâmico }\end{array}$ \\
\hline IDADE & 4 anos e meio \\
\hline
\end{tabular}

Fonte: Dos autores (2020)

\section{RESULTADOS E DISCUSSÕES}

A seguir serão descritos os procedimentos realizados no estudo de caso, o passo a passo do que se verificou no local, as manifestações patológicas e os tipos de anomalias apresentadas no residencial, proporcionando o diagnóstico e origem dos problemas, e assim classificá-los por ordem de prioridade.

As normas técnicas brasileiras correlacionadas com as obras podem ser encontradas nos registros da ABNT (Associação Brasileira de Normas Técnicas) que foram fontes de estudo para a construção do presente trabalho como, a norma NBR 13752 (ABNT, 1996) que estabelece métodos às perícias de engenharia na construção civil e determina critérios com o intuito de elaborar laudos e pareceres técnicos: a NBR 5674 (ABNT, 2012) que conduz os procedimentos de manutenção; a NBR 14037 (ABNT, 2014) que fixas diretrizes para o desenvolvimento de manuais de utilização e operação das edificações; a NBR 15 575-1 (ABNT, 2013) trata sobre condições de vida útil para os sistemas e componentes; a NBR 6118 (ABNT, 2014) que trata de projetos de estruturas de concreto e todos os procedimentos e a ISO 13 823, falando a respeito da durabilidade, desempenho e vida útil das edificações, inclusive a lei 13.032/2006 que relata da determinação, requisitos de vistorias periciais e manutenções periódicas aplicadas em edificações, independentemente de sua origem. E por fim, o órgão de extrema importância que regi todas as orientações sobre inspeção predial o IBAPE, que é separado por estado, sendo o mais importante o IBAPE/SP, esta norma é hoje a balizadora das atividades, instituindo critérios e lista de etapas a fim de que a avaliação seja metodológica e sistemática.

\subsection{Anomalias encontradas}

Durante a inspeção predial, realizada nos blocos da área de estudo, constataram-se as principais manifestações patológicas, desplacamento de revestimento cimentício (DRC), deterioração das juntas de assentamento (DJA), manchas, fissuras e infiltração, onde foram representadas na figura 1 as porcentagens de cada manifestação encontrada no condomínio. 


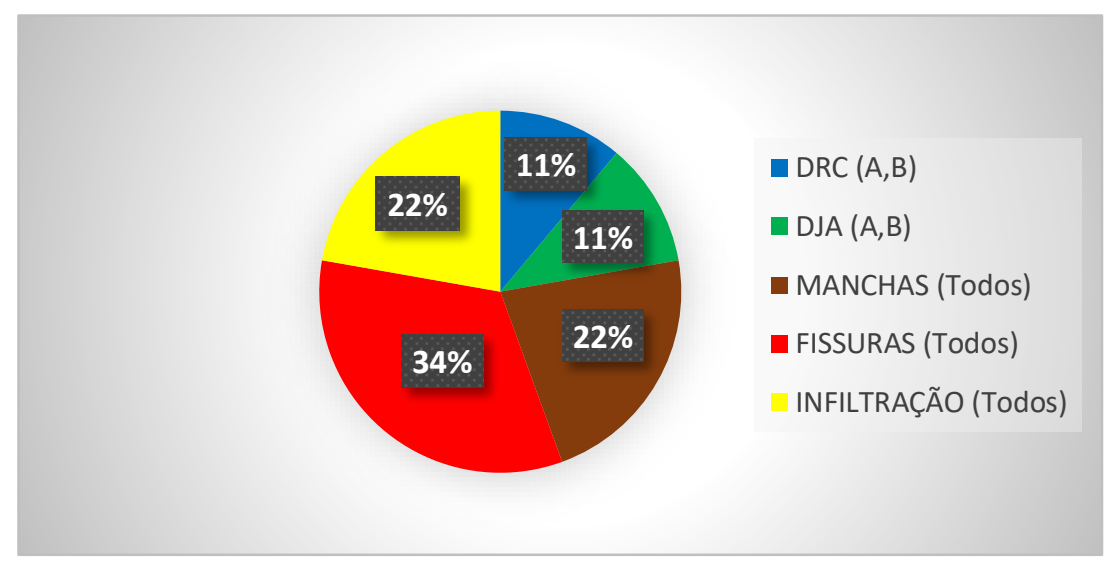

Figura 1: Esquematização dos vícios construtivos nos blocos

O percentual de fissuras foi maior no local, identificando um problema de maior complexidade, onde após a vistoria detectou problemas oriundos do solo no local, no qual requer uma atenção maior na confirmação dos fatos encontrados. A seguir no quadro 5 serão localizadas em cada bloco as manifestações patológicas citadas acima.

Quadro 5 - Representação das manifestações encontradas em cada bloco

\begin{tabular}{|c|c|c|c|c|}
\hline MANIFESTAÇÕES PATOLÓGICAS & BLOCO A & BLOCO B & BLOCO C & BLOCO D \\
\hline DESPLACAMENTO DE REVESTIMENTO CIMENTICIO & $\mathrm{x}$ & $\mathrm{x}$ & & \\
\hline DETERIORAÇÃO DAS JUNTAS DE ASSENTAMENTO & $\mathrm{x}$ & $\mathrm{x}$ & & \\
\hline MANCHAS & $\mathrm{x}$ & $\mathrm{x}$ & $\mathrm{x}$ & $\mathrm{x}$ \\
\hline FISSURAS & $\mathrm{x}$ & $\mathrm{x}$ & $\mathrm{x}$ & $\mathrm{x}$ \\
\hline INFILTRAÇÃO & $\mathrm{x}$ & $\mathrm{x}$ & $\mathrm{x}$ & $\mathrm{x}$ \\
\hline
\end{tabular}

Fonte: Dos autores (2020)

Ao longo dos resultados serão descritos as classificações das manifestações encontras e suas origens, fazendo assim uma análise comparativa geral do condomínio.

\subsubsection{Desplacamento de revestimento cimentício}

Conforme o local estava sendo analisado na inspeção preliminar, pode se perceber uma ocorrência de manifestação patológica em janelas e sacadas mostradas na figura 2, nos blocos A e B denominados de desplacamento do revestimento cimentício que nada mais é do que uma ruptura no material. É uma anomalia considerada exógena, pela origem de danos por terceiros, provocada pela má execução da grade da janela e da janela de vidro da sacada.

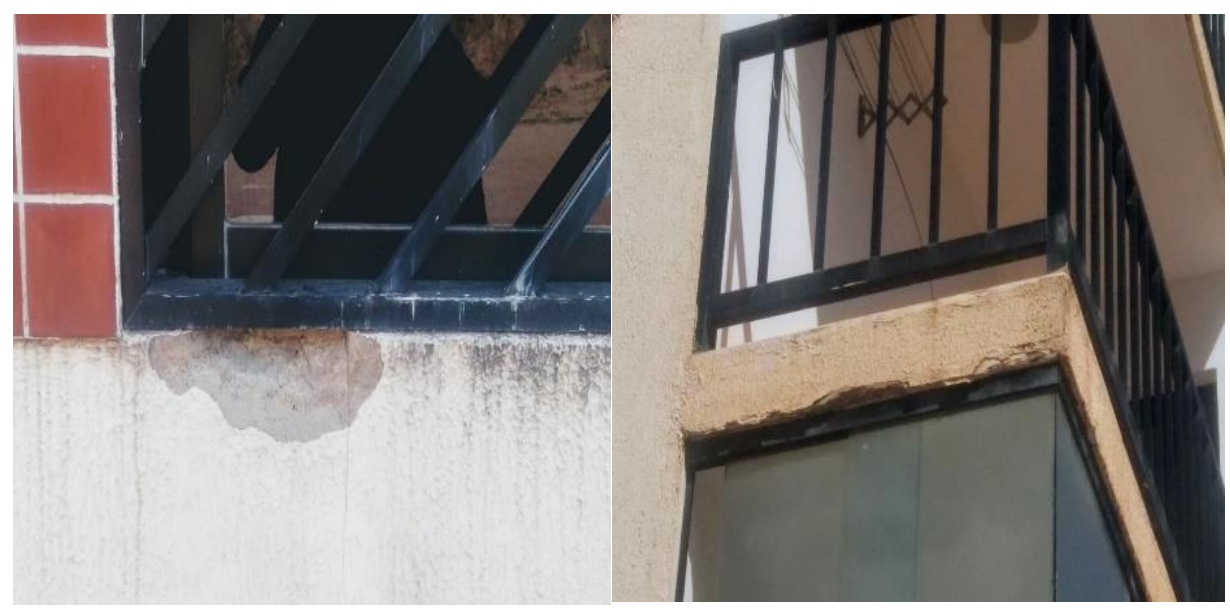

Figura 2: Desplacamentos (a) bloco A (b) bloco B 


\subsubsection{Deterioração das juntas de assentamento}

As juntas de assentamento proporcionam um alívio de tensões e otimiza a aderência das placas cerâmicas. De acordo com a inspeção, foi observado que essas propriedades das juntas de assentamento foram comprometidas, apresentando assim processo de deterioração das juntas, contribuindo para o fenômeno da eflorescência, ilustrado na figura 3. A deterioração das juntas de assentamento é classificado como anomalia endógena, por ter sua origem pela má execução do material, que leva a supor na espessura inadequada, material com baixa capacidade de absorver as deformações.

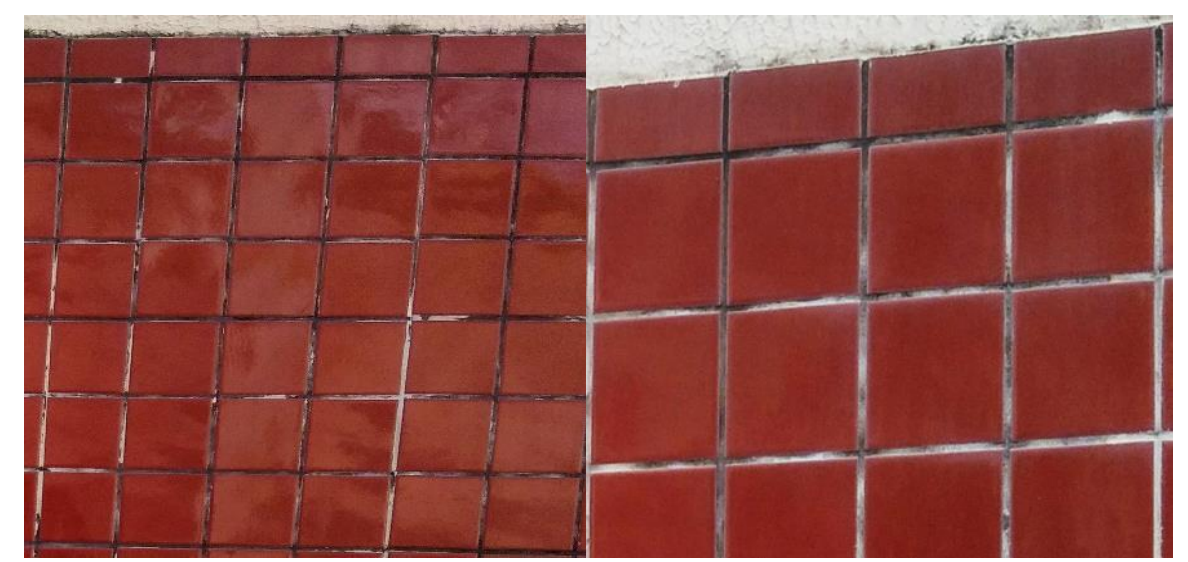

Figura 3: Deterioração das juntas de assentamento (a) bloco A (b) bloco B

\subsubsection{Manchas}

No caso de manchas apresentadas nos blocos, pode ser considerado um problema estético proveniente de mofo, saponificação, eflorescências, pingos de chuva ou da poluição urbana sobre fachadas que não recebem manutenção e sofrem com a falta de impermeabilização, mostrado na figura 4. Essa anomalia é classificada como endógena, dando sua origem através do clima, posição onde se localiza o condomínio e pela umidade do local.

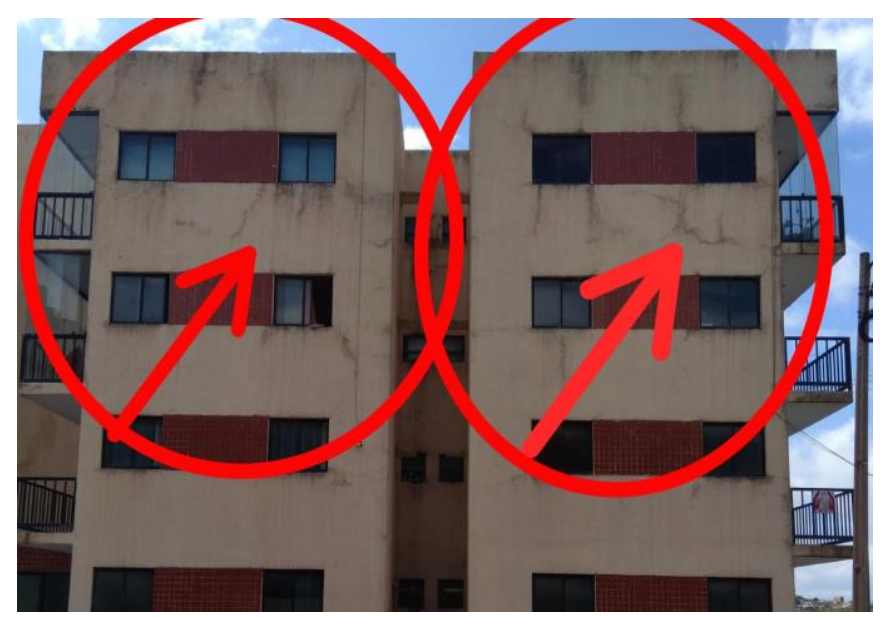

Figura 4: Manchas localizada na fachada principal do bloco A

\subsubsection{Fissuras}

Na inspeção predial, observou-se o aparecimento de fissuras nos blocos do Condomínio Residencial, fissuras essas que são apresentadas em diferentes locais dos blocos, exemplo, janelas, sacadas dos apartamentos, fachadas, escadas, no piso cerâmico, paredes e estacionamentos. A figura 5 retratam sobre o surgimento das fissuras nas janelas do bloco A, onde o mesmo padrão segue para os demais blocos. São classificadas como anomalias endógenas, tendo sua origem pelo mau dimensionamento ou falta das vergas e contra vergas no local. 


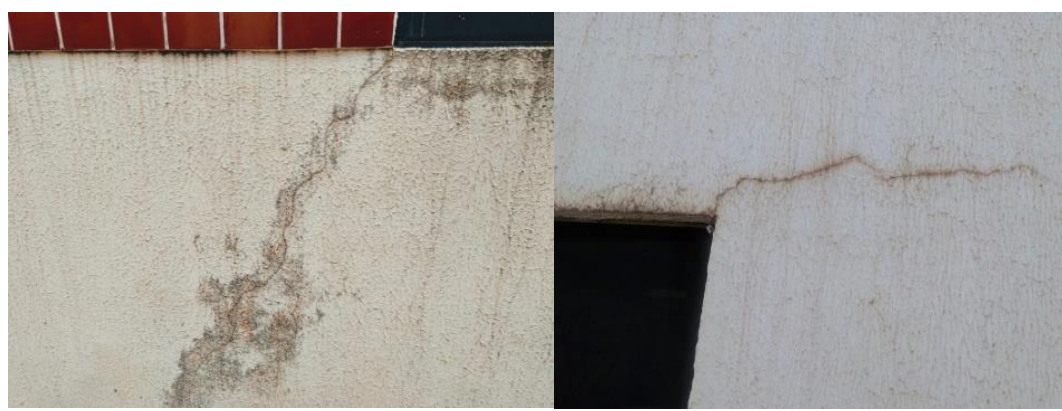

Figura 5: Fissuras apresentadas nas janelas do bloco A (a) parte inferior (b) parte superior

Contudo, ao analisar o interior de todos os blocos foram verificados o aparecimento de fissuras no bloco B, fissuras essas que se estendem do térreo até o último pavimento. Esses tipos de manifestação são classificadas como anomalia endógena. A figura 6 representa um exemplo das fissuras encontradas no local que tem como origem pela má compactação do solo aterrado no local, onde consequentemente ao surgimento de recalque diferencial provocando tais fissuras.

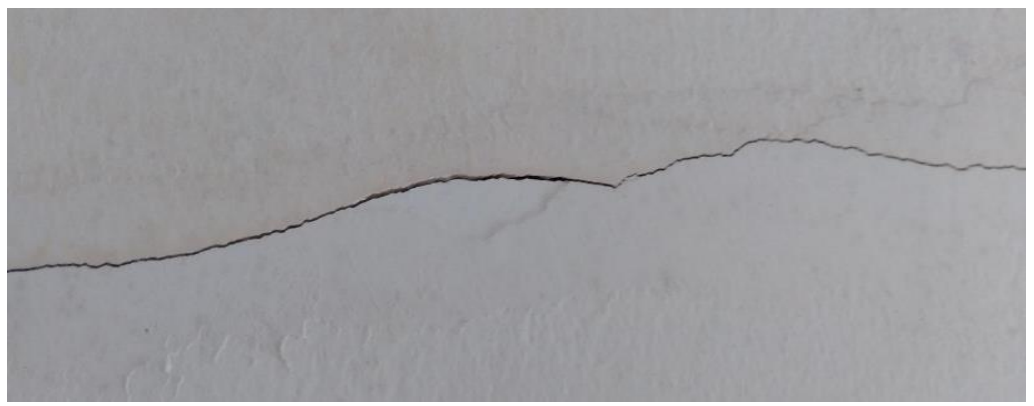

Figura 6: Fissuras localizadas no segundo andar do bloco B

Outro problema apresentado após a inspeção predial foi o aparecimento de fissuras no estacionamento dos blocos C e D, onde está ocorrendo em alguns pontos um crescimento de vegetação no local, essas fissuras são chamadas de fissuras lineares que atingem toda a espessura da placa, como é visto na figura 7, e crescimento de vegetação em algumas fissuras encontradas. Esses tipos de manifestação são classificadas como anomalia endógena. A figura abaixo é um exemplo das fissuras presentes no local, tem sua origem pela má compactação do solo aterrado.

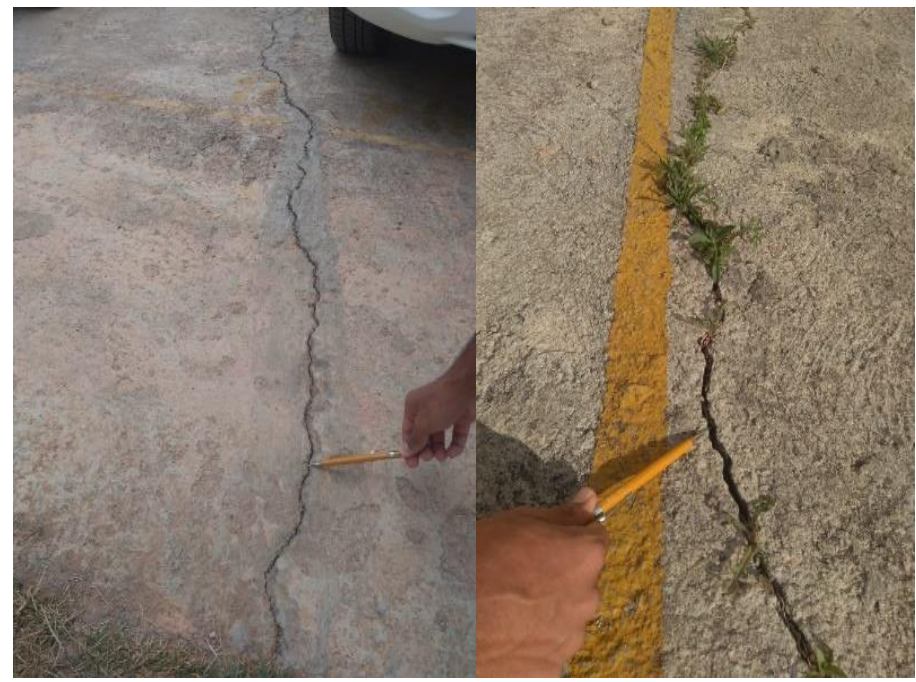

Figura 7: Fissuras presentes nos estacionamentos (a) bloco C (b) bloco D 


\subsubsection{Infiltração}

As infiltrações ocorrem por meio de outras problemas, como pontos onde haja aberturas entre materiais diferentes ou até mesmo fissuras. Ao entrar nessas fissuras podem provocar manchas, bolhas ou mofo na pintura, danificando a estrutura de concreto, o que foi observado na vistoria. A infiltração é um dano comum nas construções podendo ser descobertas nas mais diferentes edificações. Algumas infiltrações são causados quando a água consegue atravessar uma barreira protetora, chegando ao interior da estrutura, prejudicando os materiais constituintes. Na inspeção realizada foi encontro esse tipo de manifestação, onde teve a sua origem pela água parada do hall de entrada do bloco A e B e pelo vazamento da caixa d'água no último andar dos blocos. Esses problemas podem ser classificados com anomalia endógena. A figura 8 é um exemplo do que está presente no condomínio.

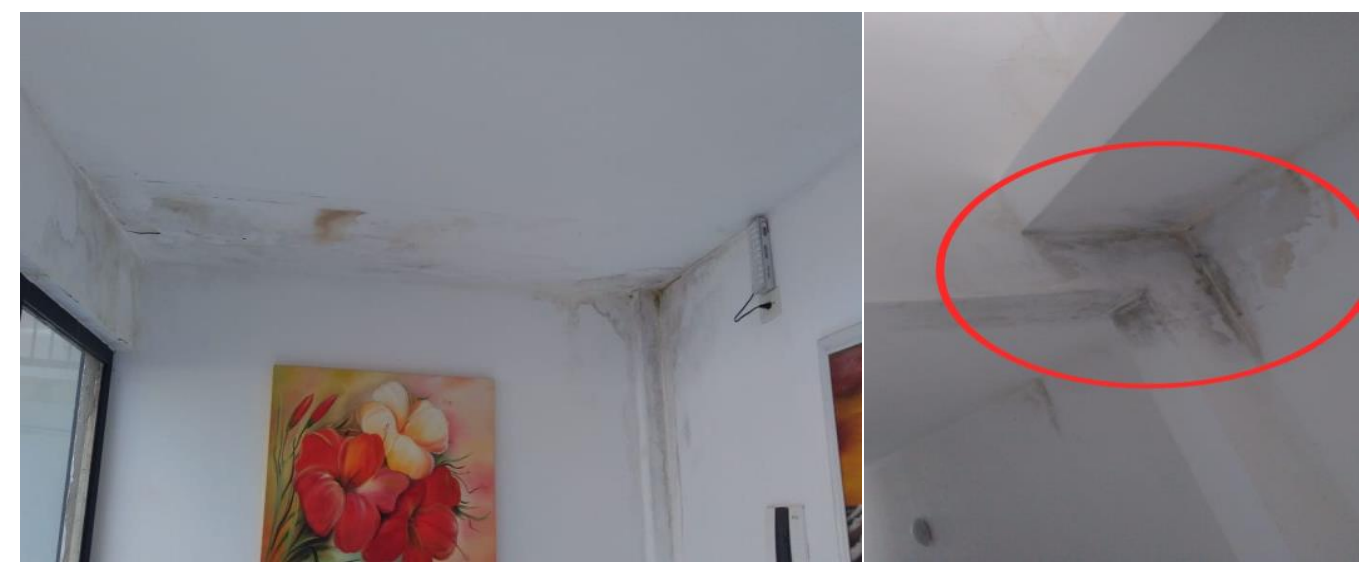

Figura 8: Infiltrações presentes no bloco A (a) hall de entrada (b) ultimo andar

Foi observado nos demais blocos o mesmo surgimento de infiltração, desgaste da pintura e manchas nos locais no último andar, nas imagens se mostra as manifestações na parede e teto acima da escada.

\subsection{Diagnóstico dos principais problemas observados}

Desta forma, após a inspeção realizada houve a classificação de cada anomalia constatada no local, que possibilitou a elaboração da figura 9, representando-as, para melhor entendimento.

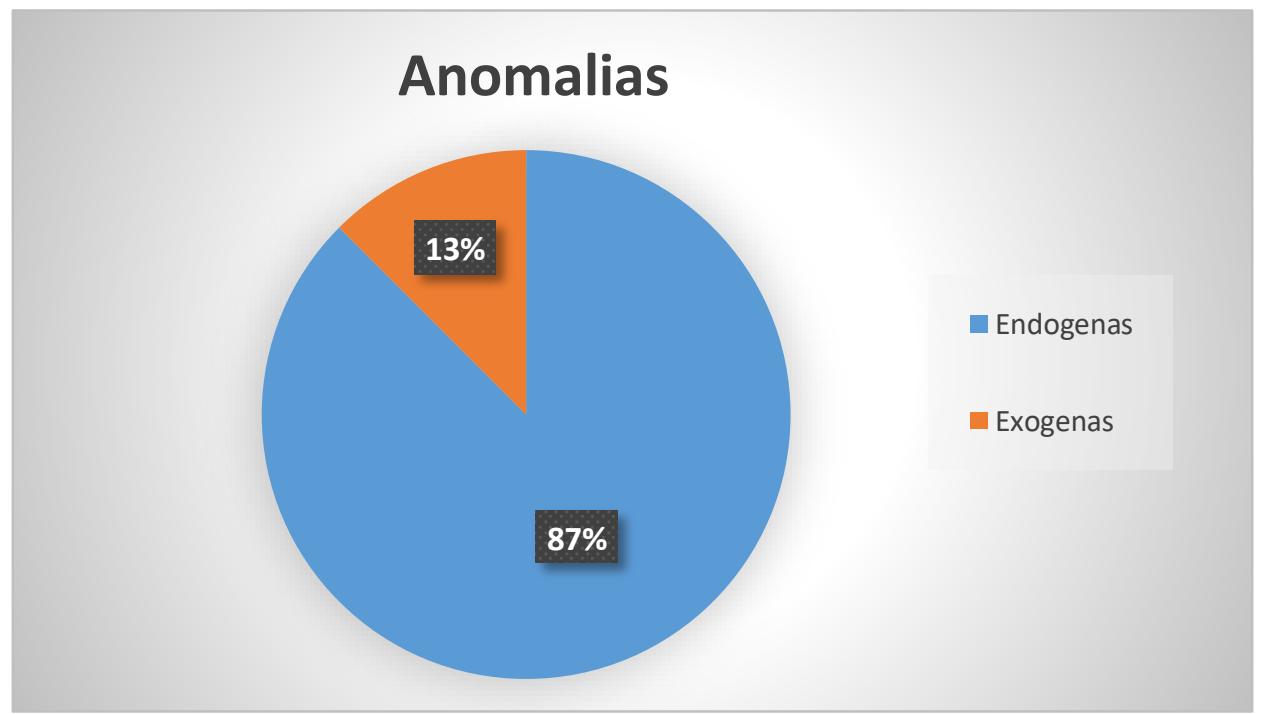

Figura 9: Porcentagem das anomalias encontradas

Observa-se que houve uma representação maior de anomalias endógenas no local, levando-nos a crer que seus vícios construtivos surgiram devido a falhas de projeto e de execução no canteiro de obras. 
3.2.1 Origens e grau de risco dos principais problemas observados

Como resultado dos levantamentos realizados, observou-se o aparecimento de manifestações patológicas nas alvenarias estruturais tendo suas origens relatadas no quadro 6.

Quadro 6 - Classificação das origens e do grau de risco

\begin{tabular}{|c|c|c|c|}
\hline BLOCO & $\begin{array}{l}\text { MANIFESTAÇÃO } \\
\text { PATOLÓGICA }\end{array}$ & ORIGEM & GRAU DE RISCO \\
\hline \multirow{5}{*}{ A } & $\begin{array}{l}\text { Desplacamento do } \\
\text { revestimento cimentício }\end{array}$ & Má execução das grades nas janelas & Regular \\
\hline & $\begin{array}{l}\text { Deterioração das juntas de } \\
\text { assentamento }\end{array}$ & Má execução do material & Regular \\
\hline & Mancha & Umidade/clima & Mínimo \\
\hline & Fissura & $\begin{array}{c}\text { Expansão e contração do material; } \\
\text { Retirada dos escoramentos fora do tempo } \\
\text { Mau dimensionamento } \\
\text { Ligação da alvenaria e estrutura } \\
\end{array}$ & Regular \\
\hline & Infiltração & $\begin{array}{l}\text { Vazamento dos reservatórios de água; } \\
\text { Água parada no teto do hall de entrada }\end{array}$ & Regular \\
\hline \multirow{5}{*}{ B } & $\begin{array}{l}\text { Desplacamento do } \\
\text { revestimento cimentício }\end{array}$ & Má execução das janelas de vidros & Mínimo \\
\hline & $\begin{array}{c}\text { Deterioração das juntas de } \\
\text { assentamento }\end{array}$ & Má execução do material & Regular \\
\hline & Mancha & Umidade/clima & Mínimo \\
\hline & Fissura & $\begin{array}{l}\text { Expansão e contração do material; } \\
\text { Retirada dos escoramentos fora do tempo; } \\
\text { Recalques diferencias provocados por má } \\
\text { compactação do solo aterrado } \\
\text { Mau dimensionamento } \\
\text { Ligação da alvenaria e estrutura }\end{array}$ & Regular/Critico \\
\hline & Infiltração & $\begin{array}{l}\text { Vazamento dos reservatórios de água; } \\
\text { Água parada no teto do hall de entrada }\end{array}$ & Regular \\
\hline \multirow{3}{*}{$\mathrm{C}$} & Mancha & Umidade/ Clima & Mínimo \\
\hline & Fissura & $\begin{array}{c}\text { Má compactação do solo aterrado } \\
\text { Mau dimensionamento } \\
\text { Ligação da alvenaria e estrutura }\end{array}$ & Regular \\
\hline & Infiltração & Vazamento dos reservatórios de água & Regular \\
\hline \multirow{3}{*}{$\mathrm{D}$} & Mancha & Umidade/ Clima & Mínimo \\
\hline & Fissura & $\begin{array}{l}\text { Má compactação do solo aterrado } \\
\text { Mau dimensionamento } \\
\text { Ligação da alvenaria e estrutura }\end{array}$ & Regular \\
\hline & Infiltração & Vazamento dos reservatórios de água & Regular \\
\hline
\end{tabular}

Fonte: Dos autores (2020)

Essas manifestações patológicas são oriundas de falha de projeto e execução no canteiro de obras, onde algumas delas poderiam ter sido evitadas com as aplicações de algumas normas, como, por exemplo, NBR 14 331/2009 para alumínio e suas ligas - telhas e acessórios - Requisitos, projeto e instalação, para minimizar o aparecimento de mancha nas fachadas dos blocos, NBR 6118/2014 para projeto de estrutura de concreto - procedimento, para a execução da obra no local e NBR 6122/2010 para projeto e execução de fundações, para evitar erros na execução das fundações com diferentes tipos de solo. Houve a necessidade de representar, de uma forma geral, a classificação do grau de risco do Condomínio Residencial para melhor compreensão e para determinar a predominância do grau de risco no local, mostrado na figura 10. 


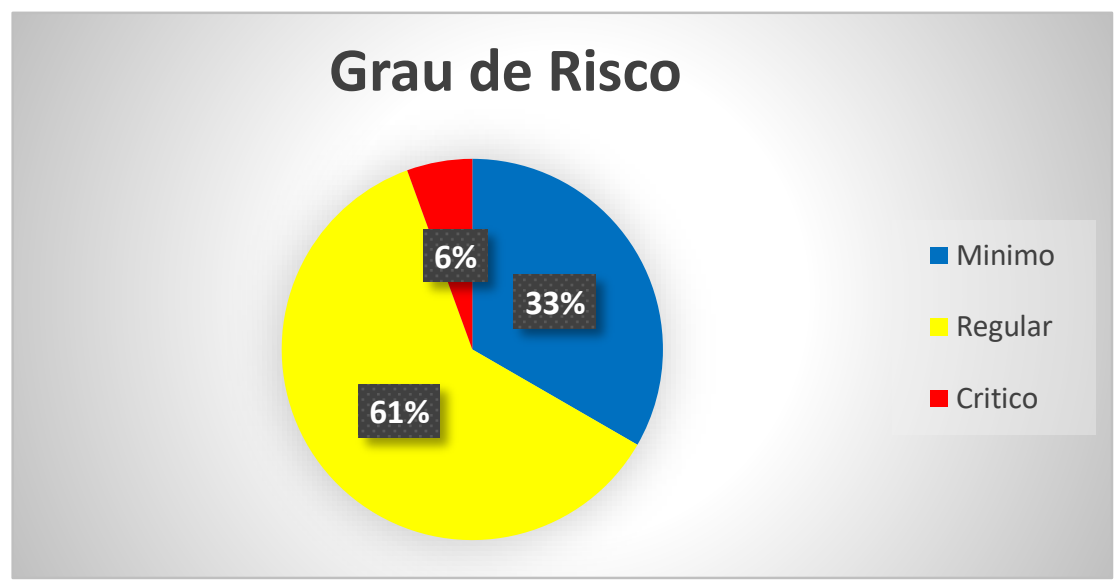

Figura 10: Representação do grau de risco no condomínio

O grau de risco regular predomina na estrutura, levando a uma preocupação maior com o desempenho, durabilidade e vida útil da edificação.

\subsubsection{Ordem de Prioridade do Condomínio Residencial}

Irá ser aplicado o método de GUT de gerenciamento de risco para descobrir a ordem de gravidade, urgência e tendência dos blocos apresentados ao longo do trabalho, fazendo assim uma comparação dos riscos mostrados nos blocos, onde DRC é Desplacamento de Revestimento Cimentício e DJA é Deterioração das Juntas de Assentamento. Será classificado a ordem de prioridade de cada bloco, começando sempre pelos cálculos mostrando a numeração, comparado com os demais, colocando assim, de uma forma decrescente, priorizando os reparos do grau maior até o menor, como é ilustrado na tabela 2.

Tabela 2 - Representação da ordem de Prioridades no Condomínio Residencial

\begin{tabular}{c|c|c|c|c|c}
\hline \multicolumn{7}{c}{ MOCAL } & PROBLEMAS & GRAVIDADE & URGÊNCIA & TENDÊNCIA & PONTUAÇÃO GUT \\
\hline \multirow{4}{*}{ BLOCO B } & DRC & 1 & 1 & 1 & 1 \\
\cline { 2 - 6 } & DJA & 6 & 6 & 6 & 216 \\
\cline { 2 - 6 } & Manchas & 3 & 3 & 3 & 27 \\
\cline { 2 - 6 } & Fissuras & 6 & 8 & 8 & 384 \\
\cline { 2 - 6 } & Infiltração & 6 & 6 & 6 & 216 \\
\hline \multirow{4}{*}{ BLOCO A } & DRC & 3 & 6 & 6 & 108 \\
\cline { 2 - 6 } & DJA & 6 & 6 & 6 & 216 \\
\cline { 2 - 6 } & Manchas & 3 & 3 & 3 & 27 \\
\cline { 2 - 6 } & Fissuras & 3 & 6 & 6 & 108 \\
\cline { 2 - 6 } & Infiltração & 6 & 6 & 6 & 216 \\
\hline & Manchas & 3 & 3 & 3 & 27 \\
\cline { 2 - 6 } & Fissuras & 6 & 6 & 6 & 216 \\
\cline { 2 - 6 } & Infiltração & 6 & 6 & 6 & 27 \\
\hline \multirow{5}{*}{ BLOCO C } & Manchas & 3 & 3 & 3 & 108 \\
\cline { 2 - 6 } & Fissuras & 3 & 6 & 6 & 216 \\
\cline { 2 - 6 } & Infiltração & 6 & 6 & 6 & \\
\hline
\end{tabular}

Fonte: Dos autores (2020)

Podemos observar que a análise numérica aplicada pela matriz GUT no que diz respeito às manifestações encontradas no Bloco B, estão em um grau elevado comparado com os demais blocos, por isso precisa priorizá-lo e começar os reparos 
o mais rápido possível, se esse método fosse posto em um ranking para priorizar os reparos o bloco B, estaria em primeiro lugar com 844, A em segundo com 675, D em terceiro com 459 e o C em quarto com 351.

\section{CONSIDERAÇÕES FINAIS}

Toda forma de edificação está sujeita a sofrer efeitos indesejáveis de manifestações patológicas, interferindo na sua qualidade, seja no aspecto estético, funcional ou estrutural. O presente trabalho foi executado a fim de esclarecer as definições de Engenharia Diagnóstica e Inspeção Predial, apresentando sua importância para detectar manifestações patológicas em edificações, o grau de risco e a ordem de prioridades. O laudo técnico de inspeção predial do Condomínio Residencial conclui que as manifestações patológicas observadas e o seu agravamento pode ser atribuídos, inicialmente, a falha de projeto e execução. Durante o processo de identificação das manifestações patológicas nos blocos, pôde-se observar que o sistema estrutural das edificações apresentam anomalias significativas sendo $87 \%$ endógenas que podem ser constatadas visualmente e classificação do grau de risco que representou $61 \%$ regular, colocando a edificação em estado de alerta e, por fim, a ordem da matriz GUT que após sua elaboração, constatou riscos iminentes apresentados no bloco B, que está com a parte estrutural comprometida, devendo ser realizados estudos, para o combate de tais problemas. Constatou-se a necessidade de fazer correções mediante as anomalias, grau de risco e ordem de prioridade detectada no local, realizando métodos que exerce o prolongamento do desempenho, durabilidade e vida útil dos blocos. Pode-se constatar que o laudo técnico de inspeção predial estudado, apontou dados suficientes para a elaboração deste trabalho. Diante do que foi citado acima e no decorrer do trabalho, garante que a inspeção predial possibilita o cuidado das edificações e ajuda na racionalização dos gastos a serem realizados com manutenções. Portanto, aponta as manutenções necessárias em conformidade com o grau de risco e urgência mostrados, assim, assegurando a saúde e segurança dos moradores e, consequentemente aumentando o desempenho, durabilidade e a vida útil das edificações. Contudo, após toda a aplicação do método de inspeção predial poderiam ser realizados no local, ensaios não destrutivo e destrutivo, para verificar a resistência, durabilidade de todos os elementos estruturais, como pacometria, esclerometria, ultrassom, extração e rompimento de testemunho, carbonatação, sondagem, entre outros.

\section{REFERÊNCIAS}

APOLONIO, P. H. Desempenho e Patologias das Construções Civis. Nota de aula. Curso de especialização em pós graduação da Faculdades Integradas de Patos. Nov. 2019.

ASSOCIAÇÃO BRASILEIRAS DE NORMAS TECNICAS. International Organization for Standardzation (ISO). ISO 13823.2008.

ASSOCIAÇÃO BRASILEIRAS DE NORMAS TECNICAS. NBR 14 037: Diretrizes para elaboração de manuais de uso, operações e manutenção das edificações e apresentação dos conteúdos. Rio de Janeiro, p. 10. 2014.

ASSOCIAÇÃO BRASILEIRAS DE NORMAS TECNICAS. NBR 13752: Pericias de engenharia na construção civil. Rio de Janeiro, p. 8. 1996.

ASSOCIAÇÃO BRASILEIRAS DE NORMAS TECNICAS. NBR 14653-1: Avaliação de bens. Parte 1: Procedimento gerais. Rio de Janeiro, p. 4. 2019.

ASSOCIAÇÃO BRASILEIRAS DE NORMAS TECNICAS. NBR 15575-1: Edificações Habitacionais Desempenho Parte 1: Requisitos gerais. Rio de Janeiro, p. 8. 2013.

ASSOCIAÇÃO BRASILEIRAS DE NORMAS TECNICAS. NBR 5674: Manutenção de edificações Procedimento. Rio de Janeiro, p. 2. 2012.

ASSOCIAÇÃO BRASILEIRAS DE NORMAS TECNICAS. NBR 6118: Projeto de estruturas de concreto Procedimento. Rio de Janeiro, p. 16. 2014.

ASSOCIAÇÃO BRASILEIRAS DE NORMAS TECNICAS. NBR 14331: Alumínio e suas ligas - telhas e acessórios. Rio de janeiro, p. 12. 2009.

ASSOCIAÇÃO BRASILEIRAS DE NORMAS TECNICAS. NBR 6122: Projeto e execução de fundações. Rio de janeiro, p. 9. 2010. 
GOMIDE, T. L. F.; PUJADAS. F. Z. A.; FAGUNDES NETO, J. C. Técnicas de Inspeção e Manutenção Predial, São Paulo ed. Pini, 2006.

IBAPE/SP (INSTITUTO BRASILEIRO DE AVALIAÇÕES E PERÍCIAS DE ENGENHARIA DO ESTADO DE SÃO PAULO). Norma de Inspeção Predial Nacional. São Paulo, 2012.

RAMALHO, M. B.; PRATES, V. D. G.; SILVA, K. G.; BASTOS, D. M.; OLIVEIRA, N. B. Avaliação das Manifestações Patológicas da Umidade de Edificações em Cidades do Vale do Jequitinhonha e Mucuri - MG. COBENGE. Engenharia: múltiplos saberes e atualidade. set. 2014. Disponível em: <

http://www.abenge.org.br/cobenge/arquivos/5/Artigos/129193.pdf>. Acesso em: 19 dez. 2019.

VIEIRA, M. A. Patologias Construtivas: Conceitos, Origens e Métodos de Tratamento. Monografia (MBA em Gerenciamento de Obras, Tecnologia e Qualidade da Construção), IPOG, Uberlândia-MG, 2016. 